\title{
Motivational Antecedents of Well-Being and Health Related Behaviors in Adolescents
}

\author{
by \\ Isabel Balaguer ${ }^{1}$, Joan L Dudaㄹ, Isabel Castillo
}

\begin{abstract}
Grounded in the Achievement Goal Theory framework of motivation and optimal functioning, there were two objectives of this study: (a) to test a model hypothesizing links between personal theories of school achievement, indices of the quality of academic engagement, wellbeing, and health-related behaviors, and (b) to explore whether the hypothesized model was invariant across gender groups. A multisection questionnaire pack tapping the targeted variables was administered to 967 teenagers (475 boys and 492 girls) aged between 11 to 16 years old. Structural equation modeling analysis revealed that Task theory of achievement predicted positively satisfaction in school and negatively boredom in school. An Ego theory of achievement was linked to higher levels of boredom in school. Satisfaction in school corresponded to higher life satisfaction, while boredom was negatively related. Higher life satisfaction was associated with lower tobacco, alcohol and marijuana consumption, more healthy food intake and greater levels of physical activity. The results revealed partial invariance of the model by gender. The quality of adolescents' involvement in the classroom holds important implications for adolescent's well-being and their health related behaviors. Interventions on the creation of a task-involving motivational climate in the school are proposed to promote healthy lifestyles among young people.
\end{abstract}

Key words: adolescent health, health determinants, school health, structural equation modeling, psychosocial theories.

\section{Introduction}

Adolescence is a developmental period in which changes on young people's lifestyle are observed. They tend to begin or increase smoking cigarettes, start drinking alcohol and using illegal drugs, and change their eating patterns. Adolescence is also a transitional stage when a marked decrease in sport and physical activity participation is observed (Kuntsche and RavensSieberer, 2015). Given the impact that health behavioral patterns of teenagers can have on their present and subsequent health, it is important to study some of the antecedents of these behaviors.

Motivation has been considered an important factor in terms of adoption and maintenance of a healthy or unhealthy lifestyle (Ryan and Deci, 2000). More specifically, it has been suggested that the enhancement of

psychological well-being and a decrease in the probability of risk behaviors during adolescence is a function of variation in motivation (Duda, 2001). The implications of these motivational processes for young people welfare have been studied in different achievement contexts, such as school and sport (Balaguer et al., 1997; Jiménez-Castuera et al., 2007; Moreno et al., 2008). In the current study, based on the Achievement Goal Theory (AGT, Nicholls, 1989), we focused on the school domain in examining the interdependencies between motivational factors and indices of optimal engagement, well-being, and the selfreported health behavior patterns of adolescents.

AGT, which is a popular and contemporary framework of motivation, offers insight into why variations in adolescents'

\footnotetext{
1 - Department of Social Psychology. University of Valencia. Spain.

2 - School of Sport Exercise and Rehabilitation Sciences. University of Birmingham - Birmingham. United Kingdom.
} 
achievement goals might influence the initiation, maintaining or abandon of an activity. This theory indicates that defining success by adolescents and judging one's competence have important consequences for an adaptive or maladaptive lifestyle. This theory holds that there are two primary goal perspectives operating in achievement contexts namely, task and ego involvement. When task-involved, perceived ability is self-referenced and emphasis is placed on task mastery, the exertion of effort, and the development of personal skills or knowledge of the activity. When ego-involved, individuals are concerned with demonstrating normatively referenced ability and, thus, perceive a successful event when they think that they have surpassed others or performed equally with less effort.

Theoretically and based on empirical studies (Duda and Nicholls, 1992; Nicholls, 1989), coherent interplay between dispositional goals (i.e., tendencies to emphasize task- and egoinvolved definitions of success) and beliefs about the causes of success in school exists. According to Nicholls (1989), these different goal-belief dimensions reflect individual differences in people's personal theories of school achievement (namely, task and ego theory); that is, they capture information regarding what adolescents want to achieve in the classroom and their views regarding how this achievement domain operates (Duda and Nicholls, 1992).

In general and aligned with theoretical tenets, a number of investigators (Castillo et al., 2001; Duda and Nicholls, 1992; Nicholls, 1989) have indicated that a focus on task-involved goals is associated with adaptive motivation-related cognitions, emotional responses, and beliefs in the academic context and in other areas of life. One of the important responses linked to task goals is the reported differential engagement in healthpromotive versus health-risky behaviors. Previous research involving teenagers (Balaguer et al., 1997; Jiménez-Castuera et al., 2007; Moreno et al., 2008) has suggested that the way adolescents judge their competence has implications for their health behavior choices. Task orientation was related positively with reported engagement in health enhancing behaviors (i.e., physical activity participation) and negatively with health risky behaviors (i.e., smoking and drug consumption).
According to Nicholls (1989), striving for achievement is experienced as a means to an end (i.e., the demonstration of superior ability) when one is ego involved. On the other hand, when an individual is task involved, an activity is experienced more as an end in itself. Drawing from these different perspectives on achievement, it has been argued that when performance goals are emphasized, this will correspond to a decreased intrinsic interest in the activity and less enjoyment, whereas task orientation will correspond to greater reported enjoyment and intrinsic motivation (Cerasoli et al., 2014; Duda, 2001; Garon-Carrier et al., 2016). Previous research (Castillo et al., 2001; Duda and Nicholls, 1992; Nicholls, 1989) has provided support for these postulates by indicating that students' endorsement of Task theory of academic achievement was related to greater enjoyment in school and less boredom. On the other hand, the emphasis placed on Ego theory was predictive of greater boredom in the classroom (Castillo et al., 2001; Duda and Nicholls, 1992; Tanaka and Murayama, 2014).

The other important construct that has been postulated as an antecedent of adolescent's health related behaviors is life satisfaction. This index of well-being is defined as the subjective judgments that a person makes about his/her own life (Diener et al., 1985). It has been postulated (Diener et al., 2013) that an assessment of life satisfaction includes tangible aspects of his or her life, weighs the good against the bad and arrives at a judgment of overall satisfaction. A child assessing his or her global life uses information from both worlds, the internal via self-reflection and the external via cues from their environment.

Life satisfaction is considered to be a good indicator of psychological strength, which should be a principal focus to promote positive development and avoid pathology across multiple contexts (Huebner et al., 2004). Cross-sectional, longitudinal, and experimental data have shown that variability in life satisfaction can precede diverse positive outcomes such as health related behaviors (Lyubomirsky et al., 2005). Associations between greater life satisfaction and engagement in positive health related behaviors have been supported in the literature (O'Malley and Johnston, 2002). Positive relationships have emerged between life satisfaction and health 
enhancing behaviors (healthy food intake and physical activity) (Stubbe et al., 2007). Research has also pointed to negative relationships between reported global life satisfaction and substance use (i.e., alcohol, tobacco and marijuana consumption) (Desousa et al., 2008; Sun and Shek, 2010). Among the studies that have been conducted on life satisfaction among children and adolescents (Proctor et al., 2009), only a few examined the relationship between satisfaction in school and life satisfaction (O'Malley and Johnston, 2002) and indicated that when teenagers felt more satisfied in school, they also felt more satisfied with their lives.

Thus, previous work has supported links between how young people tend to define achievement and their health-related behaviors (Balaguer et al., 1997; Jiménez-Castuera et al., 2007; Moreno et al., 2008). Research has also indicated that variability in adolescents' engagement in achievement domains, such as the classroom, is relevant to their overall subjective well-being (Castillo et al., 2001; Duda and Nicholls, 1992; Tanaka and Murayama, 2014). Previous studies have also pointed to interdependence between adolescents' satisfaction with their life and health behavior patterns (Desousa et al., 2008; Sun and Shek, 2010; Stubbe et al., 2007). However, to date, these findings have not been pulled together in a process model centered on the interplay between motivation-related characteristics, quality of engagement in achievement activities, well-being and health related behaviors in teenagers. Consequently the main objective of this paper was to test a sequential model specifying interrelationships among personal theories of achievement, reported satisfaction / enjoyment and boredom in the academic domain, life satisfaction, and positive and negative health related behaviors among adolescents (Figure 1).

We hypothesized that teenagers endorsing a task theory of achievement would find their activities in school more interesting and satisfying and, that when more satisfied in school, they would feel better about their own lives. A negative link between a task theory and reported boredom in the school was expected. Boredom in school would be negatively related to life satisfaction, and life satisfaction would negatively correspond to engagement in health-risky behaviors (i.e., tobacco, alcohol and marijuana consumption). Positive links between life satisfaction and targeted health-promoting behaviors (i.e., healthy food consumption, physical activity) were expected. When endorsing an ego-theory of achievement, we expected teenagers to indicate that they felt less interested in/satisfied with school and found their academic activities more boring. We also hypothesized that greater boredom in the classroom would correspond with less satisfaction with one's overall life.

A number of studies among adolescents have found that the use of tobacco, alcohol and marijuana is significantly linked together (Balaguer, 2002; Young et al., 2002), thus we assumed that the substances consumed would be interrelated. Finally, based on previous research (Castillo et al., 2001; Duda and Nicholls, 1992), we also assumed that satisfaction and boredom in school would be negatively related.

As the motivational mechanisms within this research were assumed to be comparable across gender groups, we tested the hypothesized model for both boys and girls. We expected the model to be invariant across gender.

\section{Methods}

\section{Participants}

A representative sample of 967 Spanish students (475 boys and 492 girls) between 11 and 16 years old $(\mathrm{M}=13.54 \pm 1.8$ years $)$ participated in this study. We excluded 110 students from the initial sample because of substantial missing data. The sample was selected on a random, stratified basis (relative size of each province and type of educational establishment). The maximum statistical error for the total sample was $+/-2.9 \%$, with a confidence level of $95.5 \%$.

\section{Measures}

The Health Behavior in School-Aged Children questionnaire (Wold, 1995) translated to Spanish (Balaguer, 2002) was used to measure reported health behaviors. The health behavior variables selected for this study included tobacco, alcohol and marijuana consumption, healthy food intake and frequency of physical activity. The tobacco index ranged from 6 = 'I smoke every day and smoke more than 40 cigarettes a week' to $1=$ 'I have never tried tobacco'. The alcohol index ranged from $6=$ 'I drink at least one of these 
beverages every week, and I have been drunk four times or more' to $1=$ 'I never drink alcohol beverages'. The marijuana index ranged from $6=$ 'In the last month, I have smoked marijuana more than three times' to $1=$ 'I have never tried marijuana'. The healthy food index ranged from 6 $=$ 'I eat these healthy foods more than three days a week' to 1 = 'I eat at least one of these healthy foods more than three days a week'. Finally, the physical activity index ranged from $6=$ 'I practice physical activity 6-7 times a week in sessions of more than 15-25 minutes' to $1=$ 'I never practice physical activity'. This questionnaire has acceptable reliability and validity (Samdal et al., 2000).

The Motivational Orientation Scale (Duda and Nicholls, 1992) translated to Spanish (Castillo et al., 2001) was employed to assess the adolescents' disposition goals (or ways of defining success) in the school setting. This scale has two dimensions: the task (8 items, e.g., I work really hard) and ego ( 8 items, e.g., I have the highest test scores) goal orientation. The stem for each item was, "I feel really successful when...". The participants indicated their degree of agreement on a 5-point Likert-type scale $(1=$ strongly disagree; $5=$ strongly agree). The psychometric validity of the scale had been extensively demonstrated in research on adolescents (Castillo et al., 2001; Duda and Nicholls, 1992). The task and ego goal subscales exhibited acceptable levels of internal consistency (alpha $=.82$ and .90, respectively) in this study.

The Beliefs about the Causes of Success in Classroom Scale (Nicholls, 1989) translated to Spanish (Castillo et al., 2001) was administered to measure the perceptions that students had about the role of effort (7 items, e.g., They work really hard), ability (4 items, e.g., They are smarter than others) and deceptive tactics (5 items, e.g., They know how to impress the teacher) as determinants of academic achievement. The stem for each item was, "People success if...". The students indicated their degree of agreement with the items on a 5-point Likert-type scale $(1=$ strongly disagree; $5=$ strongly agree). All subscales had demonstrated reliability and validity in previous research (Castillo et al., 2001; Duda and Nicholls, 1992). The internal reliability of these subscales in the present study was acceptable (alphas $=.73$ to .80 ). In the present study, alpha value for the Task Theory dimension (task orientation and effort) was .83 and for the Ego Theory dimension (ego orientation, ability and deceptive tactics) was .87 .

The Classroom Satisfaction Questionnaire (Duda and Nicholls, 1992) translated to Spanish (Castillo et al., 2001) was administered to assess the level of satisfaction/enjoyment within the school context (5 items, e.g., I usually enjoy learning at school) and boredom experienced at school (2 items, e.g., At school, I am usually bored). Responses to these items were indicated on a 5-point Likert-type scale $(1=$ strongly disagree; $5=$ strongly agree). The validity and reliability of these subscales in adolescents had been supported in previous research (Castillo et al., 2001; Duda and Nicholls, 1992). In the present work, alpha value for the Satisfaction/Enjoyment subscale was .80 and .76 for the Boredom subscale.

The Satisfaction with Life Scale (Diener et al., 1985) translated to Spanish (Atienza et al., 2000) was also administered. This five item questionnaire assesses the cognitive component of life satisfaction. Students are asked to indicate their level of agreement on a 5-point Likert-type scale $(1=$ strongly disagree; $5=$ strongly agree). One sample item is "The conditions of my life are excellent". The reliability and validity of this scale had been confirmed in previous investigations involving adolescents (Atienza et al., 2000). The scale demonstrated acceptable internal consistency in the present research (alpha $=.84$.).

Procedures

Ethical approval for the study was provided by the university ethics review committee. Schools were approached and asked to take part in research on adolescents' healthrelated lifestyles. The school directors granted permission to carry out the investigation. When a school did not agree to collaborate, it was replaced by another school from the same sample stratum. After providing their informed consent to participate in the study (and obtaining informed consent from their parents), the students were administered, by at least one trained assistant in a group never larger than five people, a multi-section inventory containing measures of the targeted variables. Participation was voluntary and the students were encouraged to ask questions during questionnaire 
administration. Confidentiality of the collected data was ensured.

\section{Statistical Analysis}

Descriptive statistics and intercorrelations between the variables were first calculated. Confirmatory factor analyses were performed to test factorial validity. To test the hypothesized model (Figure 1) and to explore whether the hypothesized model was invariant across gender groups, structural equation modeling analyses were conducted using LISREL 8.54. The observed correlation matrix was imputed and the robust maximum likelihood method of estimation was used. Multiple fit indices including the ratio between $\chi^{2}$ and its degrees of freedom, goodness of fit index (GFI), comparative fit index (CFI), non-normed fit index (NNFI), and root mean square error of approximation (RMSEA) were employed to assess the adequacy of the models.

\section{Results}

\section{Preliminary Analysis}

The factorial structure of all the scales was found to have satisfactory fit indices, with satisfactory factor loadings. However, in order not to extend the length of the article, full psychometric details stemming from the results of these analyses are available on request to the corresponding author.

Responses of the students showed that with the exception of the tobacco, alcohol and marijuana consumption indices in which mean scores were low (i.e., below the midpoint), all the other variables exhibited high mean scores (i.e., above the midpoint) (Table 1). Ego theory was negatively related with school satisfaction and positively related with school boredom. In contrast, Task theory and life satisfaction were positively related with school satisfaction and negatively related with school boredom. Life satisfaction was positively related with healthy food and with physical activity and negatively related with tobacco, alcohol and marijuana consumption (Table 1).

\section{The Structural Model}

The hypothesized model provided an acceptable fit to the data: $\chi 2(29)=73.19, p<.01$, $\chi 2 / \mathrm{df}=2.52, \mathrm{GFI}=.99, \mathrm{NNFI}=.96, \mathrm{RMSEA}=.04$ (Figure 2). Students who endorsed a task theory of academic achievement reported higher levels of satisfaction in school, which corresponded to higher life satisfaction. Students who endorsed an ego theory reported higher levels of boredom in school, which corresponded to lower life satisfaction. Higher life satisfaction was associated with lower tobacco, alcohol and marijuana consumption, and higher healthy food intake and physical activity. Students who endorsed a task theory also reported lower levels of boredom in school, which corresponded to lower life satisfaction.

The standardized indirect effects revealed that task theory had positive and significant indirect effects $(p<.01)$ on life satisfaction $(\beta=$ $.10)$, healthy food consumption $(\beta=.02)$ and physical activity $(\beta=.03)$, and negative indirect effects on tobacco consumption ( $\beta=-.03)$, alcohol consumption $(\beta=-.02)$ and marijuana consumption $(\beta=-.02)$. Ego theory did not have significant indirect effects.

\section{Gender Invariance Analyses}

The baseline model (model 1) of the multi-sample analyses performed across male and female groups simultaneously without imposing any constraints (unconstrained) produced an acceptable fit: $\chi^{2}(64)=189.07, p<.01$, CFI $=.94$, NNFI $=.92$, RMSEA $=.063$. Importantly, the hypothesized model was also found to fit the data adequately in each group: Males, GFI $=.96$, and Females, GFI $=.96$. The fit of the constrained model (model 2) was also adequate: $\chi^{2}(81)=$ 251.98, $p<.01$, CFI $=.94$, NNFI $=.93$, RMSEA $=$ .059 . However, the change in $\chi^{2}$ between the freely estimated model and the constrained model was significant, $\Delta \chi^{2}(15)=26.91, p<.05$. This suggested that the strength of at least one of the regression coefficients was not comparable across the two groups.

The modification indices suggested that the path from ego theory to school satisfaction could not be held invariant across gender. In model 3, this path was freely estimated for each group and the model produced an acceptable fit: $\chi^{2}(80)=$ 207.97, $p<.01, \mathrm{CFI}=.94, \mathrm{NNFI}=.93$, RMSEA $=$ .058. The chi-square difference comparing model 3 and model 1 was not statistically significant, $\Delta \chi^{2}(14)=26.91, p<.05$, suggesting that the strength of the relationship among all of the hypothesized constructs was significant across gender groups, except for the path coefficient from ego theory to school satisfaction. The 
nonequivalence identified for this regression coefficient suggests that the relationships among those constructs are moderated by gender. Specifically, the baseline model revealed that the (negative) path from ego theory to satisfaction in school was significant for females $(\beta=-.12, p<$ $.01)$, but not for males $(\beta=-.03, p>.05)$.

Table 1

Descriptive statistics and bivariate correlations among the study variables.

\begin{tabular}{|c|c|c|c|c|c|c|c|c|c|c|c|c|c|}
\hline & & Range & $M$ & $S D$ & 1 & 2 & 3 & 4 & 5 & 6 & 7 & 8 & 9 \\
\hline 1. & Ego Theory & $1-5$ & 2.76 & .65 & - & & & & & & & & \\
\hline 2. & Task Theory & $1-5$ & 4.18 & .44 & -.01 & - & & & & & & & \\
\hline 3. & School satisfaction & $1-5$ & 3.35 & .79 & $-.06^{*}$ & $.26^{*}$ & - & & & & & & \\
\hline 4. & School boredom & $1-5$ & 3.10 & .99 & $.29^{*}$ & $-.09^{*}$ & $-.53^{*}$ & - & & & & & \\
\hline 5. & Life satisfaction & $1-5$ & 3.77 & .79 & .02 & $.25^{*}$ & $.38^{*}$ & $-.14^{*}$ & - & & & & \\
\hline 6. & Tobacco consumption & $1-6$ & 2.09 & 1.57 & .07 & -.02 & $-.22^{*}$ & $.15^{*}$ & $-.34^{*}$ & - & & & \\
\hline 7. & Alcohol consumption & $1-6$ & 2.17 & 1.44 & .04 & $-.09^{*}$ & $-.23^{*}$ & $.15^{*}$ & $-.33^{*}$ & $.64^{*}$ & - & & \\
\hline 8. & Marijuana consumption & $1-6$ & 1.39 & 1.15 & .04 & -.05 & $-.20^{*}$ & $.13^{*}$ & $-.23^{*}$ & $.61^{*}$ & $.52^{*}$ & - & \\
\hline 9. & Healthy food & $1-6$ & 4.03 & 1.28 & -.07 & $.08^{*}$ & $.20^{*}$ & $-.14^{*}$ & $.24^{*}$ & -.06 & -.03 & .03 & \\
\hline 10. & Physical activity & $1-6$ & 3.48 & 1.48 & .03 & $.12^{*}$ & $.14^{*}$ & $-.11^{*}$ & $.30^{*}$ & $-.15^{*}$ & $-.13^{*}$ & $-.12^{*}$ & $.13^{*}$ \\
\hline
\end{tabular}

${ }^{*} p<.05$

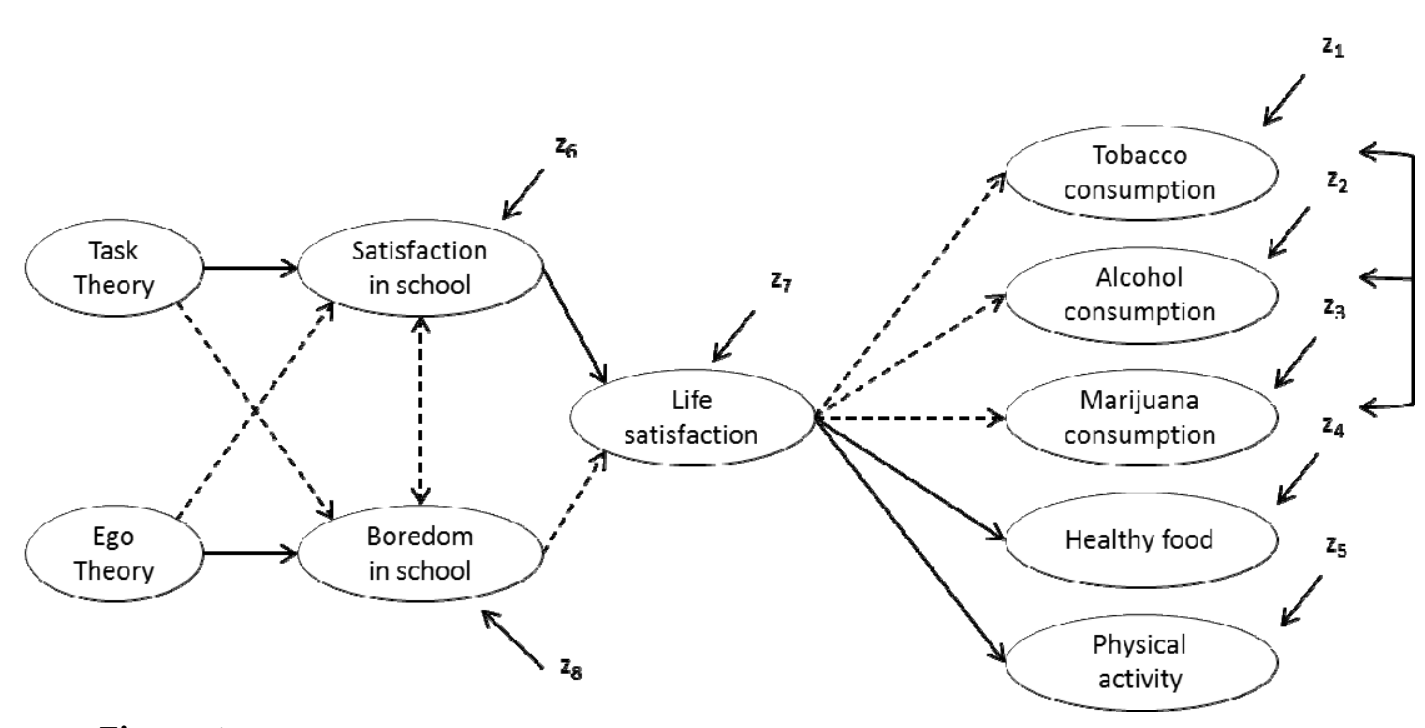

Figure 1

Hypothesized model of relationships among the variables.

Continuous lines indicate positive relationships;

discontinuous lines indicate negative relationships. 


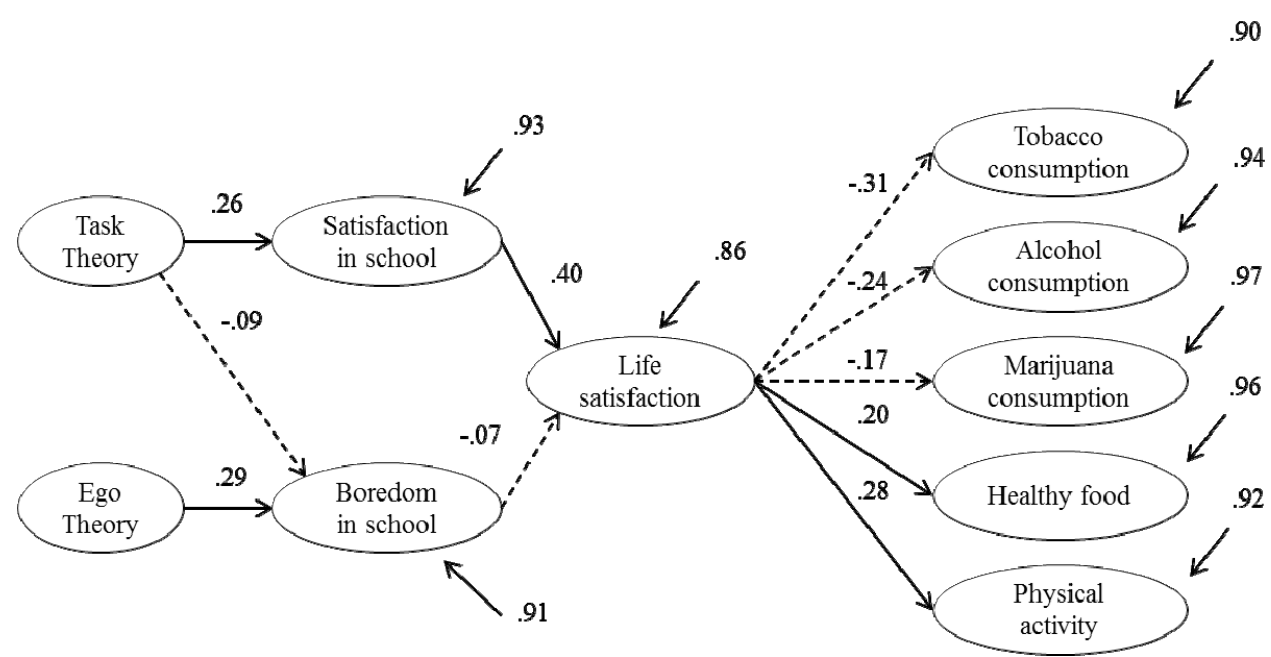

Figure 2

Standardized relationships among the variables.

All coefficients presented are standardized and significant $(z>1.96)$.

The correlations of the disturbances were as follows:

$r$ satisfaction in school-boredom in school $=-.38 ; r$ tobacco-alcohol $=.45$;

$r$ tobacco-marijuana $=.52 ;$ alcohol-marijuana $=.39$.

\section{Discussion}

Based on the Achievement Goal Theory (Nicholls, 1989), one major purpose of the present study was to test a model of motivation, specifying a sequence of interrelationships among personal theories of achievement, reported satisfaction/enjoyment and boredom in the academic domain, life satisfaction and healthpromotive and health-risky behaviors. Our results revealed that the endorsement of a task theory was positively related to reported school satisfaction and negatively related to students' experienced boredom. On the other hand, the degree of agreement with an ego theory of academic achievement was positively linked to reported boredom in the classroom. These findings are congruent with previous work (Castillo et al., 2001; Duda and Nicholls, 1992) in which task theory was found to correspond to greater satisfaction in school, and less boredom, while higher scores in ego theory were positively related to being bored in school.

The hypothesized link between ego theory and school satisfaction was the only link that was not supported in the tested model. An interpretation of such a result could be that perceived competence could have moderated this relationship. The theory (Nicholls, 1989) indicates that experienced satisfaction/enjoyment in the school domain is determined by perceptions of competence. That is, it would be expected that adolescents endorsing a task theory would enjoy and be engaged in school regardless of whether they perceive themselves as competent or not. In contrast, when an ego theory is emphasized, it is predicted that perceptions of competence will moderate levels of satisfaction/enjoyment in the school domain. If a student adopts an ego theory perspective on academic achievement and feels highly competent in his/her academic activities, then it makes sense that this student would be likely to experience positive emotions and engagement. On the other hand, endorsement of an ego theory coupled with doubts about competence would translate into more negative effect and greater disengagement.

Variability in school satisfaction/boredom and overall life satisfaction was introduced as a possible mechanism to explain the interplay between personal theories of academic achievement and health related behaviors. Both hypothesized paths were supported. We found that when adolescents were satisfied in school 
they felt more satisfied with their lives in general. In contrast, when they felt bored, then they tended to report being more unsatisfied with their lives. These findings are aligned with previous work (Atienza et al., 2000) suggesting that feeling satisfied and engaged in academic endeavors, which represents one of the major life domains in adolescence, is associated with teenagers holding a more positive appraisal of their life overall, whereas the negative link between feeling bored and satisfaction with life is consonant with the notion that boredom in adolescents is not simply a case of feeling uninterested and/or experiencing tedium or a lack of activity. Rather, when teenagers are bored, this is a maladaptive and dysfunctional emotional state that is associated with a wide range of undesirable social and psychological problems (LePera, 2011).

The five proposed links between life satisfaction and positive and negative healthrelated behaviors were fully supported. As found in previous studies (Stubbe et al., 2007), when adolescents are satisfied with their lives they seem more likely to take care of themselves by protecting their health. Furthermore, as being active and engaging in healthy eating would be expected to contribute to the maintenance of a healthy weight (e.g., prevention of obesity), this may constitute another reason for the observed association.

With respect to the negative relationship between substance use and the degree of satisfaction felt for one's life, our results are in agreement with previous research indicating that smoking cigarettes, smoking marijuana, regular alcohol use, and other selected substance-use behaviors are associated with reduced life satisfaction (Stubbe et al., 2007; Sun and Shek, 2010).

In summary, our results lend credence to the premise that variability in mental health and optimal functioning is related to variation in motivational processes (Duda, 2001; Ryan and Deci, 2000). However, more research is warranted to determine whether the observed positive relationships between the endorsement of a task theory of achievement and indices of engagement and well-being in particular, would emerge in other achievement domains (such as the athletic context).

The motivational mechanisms examined in this study are assumed to be comparable across gender groups (Nicholls, 1989). The results from the SEM multi-sample analyses partially supported the invariance hypothesis. For females the emphasis placed on an Ego theory corresponded to less enjoyment in the classroom but not for males. As mentioned above, achievement goal theory (Nicholls, 1989) suggested that perceptions of competence would moderate the relationship between an emphasis on ego goals (and associated beliefs) and cognitive, emotional, and behavioral outcomes. In particular, it is expected that any potentially maladaptive, negative effects of an emphasis on ego goals would be more evidenced when perceived competence is low. Previous research has indicated that young females, when contrasted to their male counterparts, are more likely to doubt their academic competence (Wigfield et al., 2015). If the girls in the present sample questioned their academic competence more than the boys, it is not surprising that greater importance placed on an ego theory would correspond to lower satisfaction/enjoyment in female adolescents than it is the case for male adolescents. In future work, it would be important to assess perceptions of competence and specifically consider potential interactions between perceived competence and personal theories in predicting variability in students' academic engagement and related outcomes.

\section{Limitations}

One of the limitations of the current study is that it was a cross-sectional study and in consequence, we cannot be sure whether the proposal directions in the model are really supported. Future longitudinal studies should explore the direction of these associations. We need to know whether increasing students' involvement in and satisfaction with their classwork makes them feel more satisfied with their lives per se, and less bored, or whether feeling satisfied with their lives makes them be more positive about and actively engaged in their academic tasks and less bored. We also have to test in a longitudinal approach whether higher or lower life-satisfaction predicts subsequent healthy or unhealthy behaviors or whether engagement in health promoting behaviors or health risk behaviors contributes to more or less satisfaction 
with life. Moreover, we need to discern whether life satisfaction is more of an individual difference personal variable that corresponds to adolescents tending to feel good about themselves and caring about their lives, independent or in conjunction with the surrounding circumstances (Heller et al., 2004) or whether in contrast, as suggested in this study, life satisfaction is related to more specific situational factors such as the quality of the engagement in school or leisure domains.

\section{Conclusions}

The results lend credence to the premise that variability in health and optimal functioning in academic setting is related to variation in motivational processes (Duda, 2001).
Furthermore, considering the present results, it could be suggested that the quality of adolescents' involvement in the classroom holds significance for their views regarding their lives as a whole. Finally, we found the adolescents' level of life satisfaction to be predictive of their reported positive as well as risky health related behaviors. Thus, to promote students' motivation to learn is one important starting point to their optimal development in the academic achievement and in their life overall. With the objective of promoting healthy lifestyles among young people, present findings point to the promise and potential of interventions centered on facilitating taskinvolving motivational climates in school settings.

\section{References}

Atienza FL, Pons D, Balaguer I, García-Merita ML. Psychometric properties of the Satisfaction with life Scale in Adolescents. Psicothema, 2000; 12: 331-336

Balaguer I, ed. Lifestyles in the Adolescence. Valencia: Promolibro; 2002

Balaguer I, Castillo I, Tomás I, Duda JL. Goal orientations as predictors of adolescents' health behaviors. IberPsicología, 1997; 2: 2-10

Castillo I, Balaguer I, Duda JL. Goal perspectives of adolescents in the academic context. Psicothema, 2001; 13: 79-86

Cerasoli CP, Nicklin JM, Ford, MT. Intrinsic motivation and extrinsic incentives jointly predict performance: A 40-year meta-analysis. Psychol Bull, 2014; 140: 980-1008

Desousa C, Murphy S, Roberts C, Anderson L. School policies and binge drinking behaviors of school-aged children in Wales: A multilevel analysis. Health Educ Res, 2008; 23: 259-271

Diener E, Emmons R, Larsen RJ, Griffen S. The Satisfaction with Life Scale. J Pers Assess, 1985; 2: 71-75

Diener E, Inglehart R, Tay L. Theory and Validity of Life Satisfaction Scales. Soc Indic Res, 2013: 112: 497-527

Diener E, Lucas RE, Oishi S. Subjective Well-Being and Life Satisfaction. In: Snyder CR, Lopez SJ, eds. Handbook of Positive Psychology. New York: Oxford University Press; 2002; 63-73

Duda JL, Nicholls JG. Dimensions of achievement motivation in schoolwork and sport. J Educ Psychol, 1992; 84: $1-10$

Duda JL. Goal perspectives research in sport: pushing the boundaries and clarifying some misunderstanding. In: Roberts GC, ed. Advances in motivation in sport and exercise. Champaign, IL: Human Kinetics; 2001: 129-182

Garon-Carrier G, Boivin M, Guay F, Kovas Y, Dionne G, Lemelin, J-P, Séguin JR, Vitaro F, Tremblay RE. Intrinsic motivation and achievement in mathematics in elementary school: A longitudinal investigation of their association. Child Dev, 2016; 87: 165-175

Heller D, Watson D, Ilies R. The role of person versus situation in life satisfaction: A critical examination. Psychol Bull, 2004; 130: 574-600

Huebner ES, Suldo SM, Smith LC, McKnight CG. Life satisfaction in children and youth: Empirical foundations and implications for school psychologists. Psychol Schools, 2004; 41: 81-93 
Jiménez-Castuera R, Cervelló-Gimeno E, García-Calvo T, Santos-Rosa FJ, Iglesias-Gallego D. Study of the relationships between motivation, extracurricular sport practice and food and sleep habits in students of physical education. Int J Clin Hlth Psyc, 2007, 7: 385-401

Kuntsche E, Ravens-Sieberer U. Monitoring adolescent health behaviours and social determinants crossnationally over more than a decade: introducing the Health Behaviour in School-aged Children (HBSC) study supplement on trend. Eur J Public Health, 2015; 25: 1-3

Lyubomirsky S, King L, Diener E. The benefits of frequent positive affect: Does happiness lead to success? Psychol Bull, 2005; 131: 803-855

LePera N. Relationships between boredom proneness, mindfulness, anxiety, depression, and substance use. New Sch Psychol Bull, 2011; 8: 15-25

Moreno JA, González-Cutre D, Cervelló E. Motivation and health in the physical-sport practice: differences by alcohol and tobacco consumption. Int J Clin Hlth Psyc, 2008; 8: 483-494

Nicholls JG. The competitive ethos and democratic education. Cambridge, MA: Harvard University Press; 1989

O'Malley PM, Johnston LD. Epidemiology of alcohol and other drug use among American college students. J. Stud. Alcohol, 2002; Supplement No. 14: 23- 39

Proctor CL, Linley PA, Maltby J. Youth life satisfaction: A review of the literature. J Happiness Stud, 2009; 1: $583-630$

Ryan RM, Deci E. Self-determination theory and the facilitation of intrinsic motivation, social development, and well-being. Am Psychol, 2000; 55: 68-78

Samdal O, Wold B, Klepp KL, Kannas L. Students' perception of school and their smoking and alcohol use: A cross-national study. Addict Res, 2000; 8: 141-167

Sun RC, Shek DT. Life satisfaction, positive youth development, and problem behaviour among Chinese adolescents in Hong Kong. Soc Indic Res, 2010; 95: 455-474

Stubbe JH, de Moor MHM, Boomsma DI, de Geus EJC. The association between exercise participation and well-being: A co-twin study. Prev Med, 2007; 44: 148-152

Tanaka A, Murayama K. Within-person analyses of situational interest and boredom: Interactions between task-specific perceptions and achievement goals. J Edu Psychol, 2014; 106: 1122-1134

Wigfield A, Eccles JS, Fredricks JA, Simpkins S, Roeser RW, Schiefele U. Development of achievement motivation and engagement. In: Lerner RM, Lamb ME, eds. Handbook of Child Psychology and Developmental Science. Vol 3 Socioemotional Processes. New Jersey, NJ: John Wiley \& Sons, Inc; 2015: 1-44

Wold B. Health-Behavior in schoolchildren: A WHO cross-national Survey. Resource Package Questions 1993-94. Norway: University of Bergen; 1995

Young S, Corley RP, Stallings MC, Rhee SH, Crowley TJ, Hewitt JK, et al. Substance use, abuse and dependence in adolescence: Prevalence, symptom profiles and correlates. Drug Alcohol Depen, 2002; 68: 309-322

\section{Corresponding author:}

\section{Isabel Castillo}

Department of Social Psychology. University of Valencia.

Ave Blasco Ibañez, 21

46010 - Valencia. Spain

Phone: +34 963864577

Fax: +34 963864668

E-mail: Isabel.Castillo@uv.es 